\title{
Worst-case scenarios for horizontal gene transfer from Lactococcus lactis carrying heterologous genes to Enterococcus faecalis in the digestive tract of gnotobiotic mice
}

\author{
Carl-Alfred ALPERT, Denis D.G. MATER, Marie-Claude MULLER, Marie-France OURIET, Yvonne DUVAL-IFLAH \\ and Gérard CORTHIER*
}

Unité d'Ecologie et de Physiologie du Système digestif, INRA, 78352 Jouy-en-Josas, France

\begin{abstract}
Since genetically modified (GM) lactic acid bacteria (LAB) might be released in open environments for future nutritional and medical applications, the purpose of this study was to determine an upper limit for the horizontal gene transfer (HGT) in the digestive tract (DT) from Lactococcus lactis carrying heterologous genes (lux genes encoding a bacterial luciferase) to Enterococcus faecalis. Two enterococcal wide host-range conjugative model systems were used: (i) a system composed of a mobilizable plasmid containing the heterologous lux genes and a native conjugative helper plasmid; and (ii) a Tn916-lux transposon. Both systems were tested under the most transfer-prone conditions, i.e. germfree mice mono-associated with the recipient $E$. faecalis. No transfer was observed with the transposon system. Transfers of the mobilizable plasmid carrying heterologous genes were below $10^{2}$ transconjugants per $\mathrm{g}$ of faeces for a single donor dose and reached between $10^{3}$ and $10^{4}$ transconjugants per $\mathrm{g}$ of faeces when continuous inoculation of the donor strain was used. Once established in mice, transconjugants persisted at low levels in the mouse DT.
\end{abstract}

Key words: Lactococcus lactis / Enterococcus faecalis / horizontal gene transfer / conjugative transposon / conjugative and mobilizable plasmids / digestive tract / luciferase / genetically modified bacteria / gnotobiotic mice

Abbreviations: DT: digestive tract; GM: genetically modified; GMO: genetically modified organism; HGT: horizontal gene transfer; LAB: lactic acid bacteria.

\section{INTRODUCTION}

Modern molecular biological methods now allow directed genetic modifications of many living organisms for nutritional and medical purposes. This applies especially to lactic acid bacteria (LAB), (Mercenier et al., 2003; Renault, 2002). Living genetically modified (GM) bacteria are designed to be used in open systems including the digestive tract (DT) and will finally be released in the environment (Bumann et al., 2000; Corthier and Renault, 1999; Mercenier et al., 2000; Robinson et al., 1997; Steidler et al., 2000). These developments raise concerns about safety. The transfer of heterologous genes to the digestive microflora must thus be considered.

Horizontal gene transfer (HGT) was described in complex environments. Germfree mice, associated with a known microflora, were previously used to follow plasmid transfers from L. lactis to various bacterial species (Gruzza et al., 1992; Gruzza et al., 1994). Transfers were only observed into Enterococcus faecalis (Gruzza et al., 1994). Otherwise, conjugative transposition from Bacillus subtilis to a mixed species oral biofilm developed in a fermenter was first demonstrated recently (Roberts et al., 1999). Such findings encourage studying the transfer of GM transposons or plasmids between LAB in the DT.

Conjugative plasmids and genetic elements like the enterococcal conjugative transposon Tn916 (Bertram et al., 1991; Poyart et al., 1995) represent, in nature, an important mode for HGT to a broad host-range of recipients. They may actually have wide evolutionary

\footnotetext{
* Corresponding author:
}

Tel.: 33-1 346524 67; fax: 33-1 346524 62; e-mail: corthier@jouy.inra.fr 


\section{C.-A. Alpert et al.}

consequences (Davison, 1999). A general trend in the construction of recombinant bacteria intended for environmental release is the removal of unnecessary heterologous DNA, especially of those elements which could contribute to the further dissemination of the newly inserted genes (Davison, 2002). This can be done e.g. by the use of a conjugative "helper" plasmid that can mobilize a second plasmid carrying the heterologous gene of interest. In the final construct the helper plasmid is eliminated, thus preventing the direct transfer of the mobilizable GM plasmid to secondary hosts. However, conjugative plasmids are present in nature and might be recovered by GM cells carrying the mobilizable plasmid, thereby re-establishing the complete transfer mechanism. The use of a complete helper/mobilizable system would lead to establish an upper rate limit at which in vivo mobilization might occur. Some available systems would be useful to assess this point. For instance, a helper/ mobilizable plasmid system has been described for recombination in lactococci (Langella et al., 1993) and was recently used to clone genes in non-transformable LAB (Thompson et al., 2001).

Transposons used for strain construction have been modified by the elimination of the transposase from the mobile element and provision of the transposase in trans in such a way that it can be eliminated after transfer (Davison, 2002). Experimental data are needed to ensure that exogenous natural transposons might not unlock the minitransposon which, in turn, might escape GM cells and possibly spread. In this situation, an upper limit for in vivo transposition must also be determined. A transposon approach using Tn916 was proposed to modify L. lactis (Goupil-Feuillerat et al., 2000). The interest of this model system is highlighted by the recent finding that $\mathrm{Tn} 916$ is unable to transfer in vitro from L. lactis to other bacteria (Marra et al., 1999). This system is thus similar to the situation created by a locked minitransposon and, if non-transferable in vivo, might be suitable to prevent GM-LAB spread.

In this study, we consider that these systems (helper/ mobilizable system and Tn916 transposon in L. lactis) are useful as models for plasmidic and chromosomal constructions to determine an upper limit for the HGT from GM L. lactis to E. faecalis in the DT. We expand here the genetic model by the insertion of the Vibrio harveyi luciferase reporter genes (lux) as an example for heterologous genes of interest. Luciferase activity is frequently used as an easily detectable reporter function in LAB (Corthier et al., 1998; Drouault et al., 2002). Moreover, $V$. harveyi is not a member of the DT and the lux genes are absent from the DT flora. Their detection, both by activity measurements or PCR, is therefore unambiguously an indicator for the presence of these heterologous genes and is independent of antibiotic selection.

In this work, we chose E. faecalis as the recipient strain since (i) previous plasmid transfer experiments showed that E. faecalis transconjugants could be recovered from the mice DT (Gruzza et al., 1994); (ii) it is closely related to the natural sources of the conjugative systems used and should thus easily allow the selection of stable transconjugants; and (iii) it is present in the human DT flora in subdominant numbers and therefore of significant ecological importance. In order to enhance even more the interaction and thus the transfer possibilities between donor L. lactis and recipient E. faecalis cells, we use here the gnotobiotic monoassociated mouse model, where E. faecalis is known to establish in the DT at titers far higher than in a complete complex DT flora.

Overall, we used an animal model and genetically modified constructs that are considered to be very favorable for transfer, i.e. we created a worst-case scenario, in order to estimate an upper rate limit at which HGT might occur.

\section{RESULTS}

\section{Mobilizable plasmid}

\section{In vitro conjugation}

In conjugation experiments with the donor L. lactis CA33 and the recipient $E$. faecalis Z1666, transfer of the mobilizing pIL205 occurred at $1.3 \times 10^{-2}$ per donor, while co-mobilization of pCAC4 was significantly lower with a transfer rate at $4.6 \times 10^{-4}$ per donor. Using CA31 as the donor, co-mobilization of pCAC2 was even lower since the transfer rate reached only $4.8 \times 10^{-8}$. When the plasmid extracted from the transconjugant was reintroduced in L. lactis 1403 by electroporation, luciferase activity levels as in the original strain were observed, indicating that there was a genuine transfer of the plasmid between L. lactis and E. faecalis.

\section{In vivo conjugation}

We performed conjugation experiments in mice, which were associated with E. faecalis (Fig. 1). In a single dose experiment, the titer for the donor L. lactis CA33 in the faeces dropped within four days by approximately $6 \operatorname{logs}$, while the titer for the enterococci remained quite stable at 


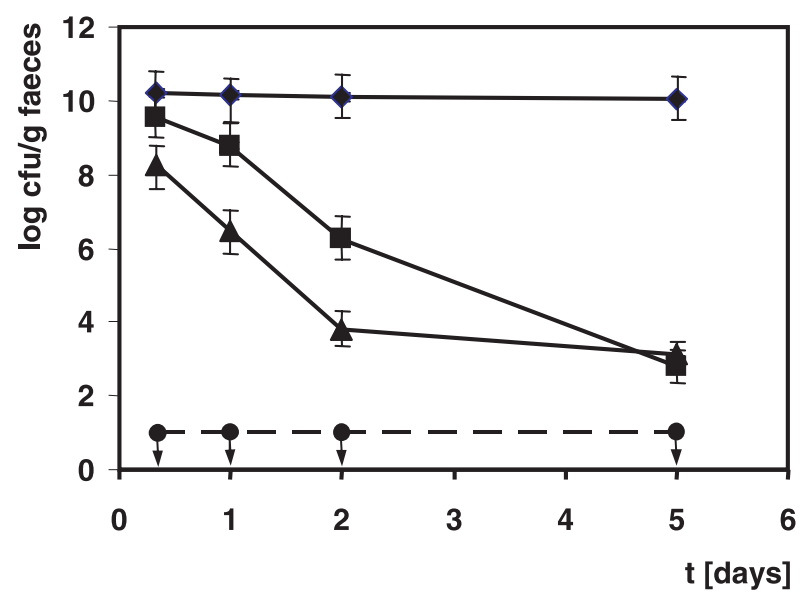

Figure 1. In vivo conjugation of pIL205/pCAC4 from L. lactis CA33 in mice associated with E. faecalis Z1666, single dose experiment. Diamonds indicate E. faecalis Z1666, squares L. lactis CA33, triangles E. faecalis Z1666/pIL205, circles E. faecalis Z1666/pIL205/pCAC4. Down arrows indicate values below the detection limit.

or above $1 \times 10^{10} \mathrm{CFU} . \mathrm{g}^{-1}$ of faeces. One day after inoculation with the donor strain, E. faecalis transconjugants containing pIL205 were observed at titers between $1 \times 10^{3}$ and $1 \times 10^{4} \mathrm{CFU}_{\mathrm{g}}{ }^{-1}$ of faeces (Fig. 1). This titer remained stable throughout the experiment. E. faecalis transconjugants containing pIL205 as well as pCAC4 were found on days 1 through 4 after inoculation, then decreased to a non-detectable level on day seven (Fig. 1). In order to permit the donors to interact longer or at higher numbers with the recipients, transfer was assessed with continuous dosage of the donor bacteria during 4 days (Fig. 2). By this means, the titer of $L$. lactis detected in the faeces rose from $10^{8}$ CFU.g ${ }^{-1}$ at day 1 to about $10^{10} \mathrm{CFU}_{\mathrm{g}}{ }^{-1}$ at day 4, where it leveled off. E. faecalis transconjugants containing pIL205 reached levels between $1 \times 10^{4}$ and $1 \times 10^{5} \mathrm{CFU}_{\mathrm{g}^{-1}}$ faeces, while transconjugants containing pIL205 and pCAC4 remained about two logs below this titer (Fig. 2).

Conjugation experiments in mice were also made with CA31 as the donor (data not shown). A single transconjugant $E$. faecalis (CA61) was detected on day 4, harboring both the conjugative pIL205 and the mobilizable pCAC2. This low transfer frequency of the co-mobilizable plasmid was also confirmed when, in two additional series of continuous dosage of the donor strain, no further transconjugant was observed.

Plasmid stability of the CA61 E. faecalis transconjugant obtained in vivo was assessed in germfree mice. The

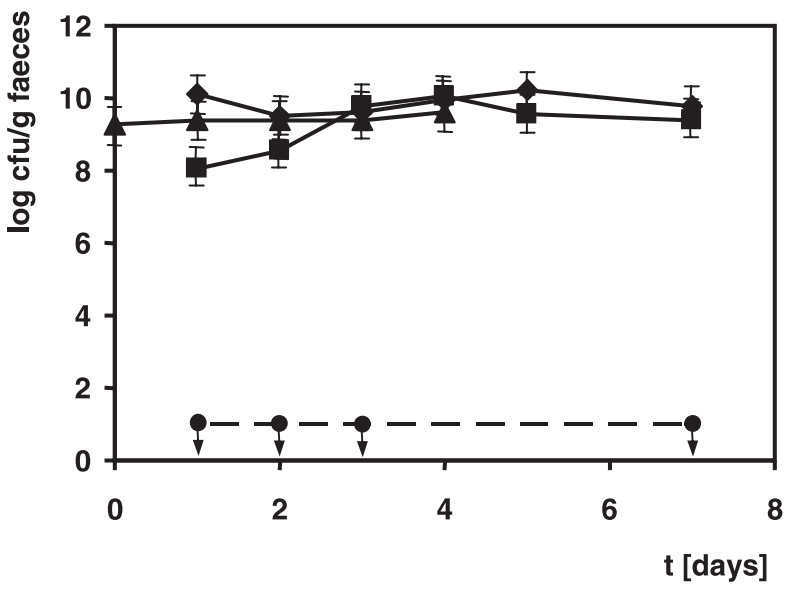

Figure 2. In vivo conjugation of pIL205/pCAC4 from $L$. lactis CA33 in mice associated with E. faecalis Z1666, continuous dose experiment (during 4 days). Diamonds indicate $E$. faecalis Z1666, squares L. lactis CA33, triangles $E$. faecalis Z1666/pIL205, circles E. faecalis Z1666/pIL205/pCAC4.

strain established at the same levels as observed before for the E. faecalis recipient. It did not loose pIL205 as well as pCAC2 plasmids for a period of two months.

\section{Conjugative transposon}

\section{In vitro transfer}

Since it is known that L. lactis is unable to transfer $\operatorname{Tn} 916$ to other hosts in vitro, the transferability of the modified transposon was first ascertain with a $B$. subtilis donor. This step was also useful to obtain a variety of hosts harboring Tn916-lux for subsequent experiments. The conjugation from B. subtilis to L. lactis IL1403 occurred at rates of up to $6.4 \times 10^{-7}$ transconjugants/donor, which confirms that Tn916-lux can still conjugate at a detectable rate after its modification. However, when the L. lactis transconjugant (CA3) was used as the donor in a consecutive mating experiment with $E$. faecalis TTC00.0395 as a recipient, no transconjugant was obtained $\left(<2.2 \times 10^{-10}\right.$ transconjugants/donor).

\section{In vivo transfer}

Germfree mice were associated with E. faecalis TTC00.0395, which established at a titer about $10^{10} \mathrm{CFU}^{-1}{ }^{-1}$ of faeces. When L. lactis CA3 was given by a single oro-gastric intubation, more than $10^{9} \mathrm{CFU}_{\mathrm{g}} \mathrm{g}^{-1}$ of faeces were detected for the lactococci 


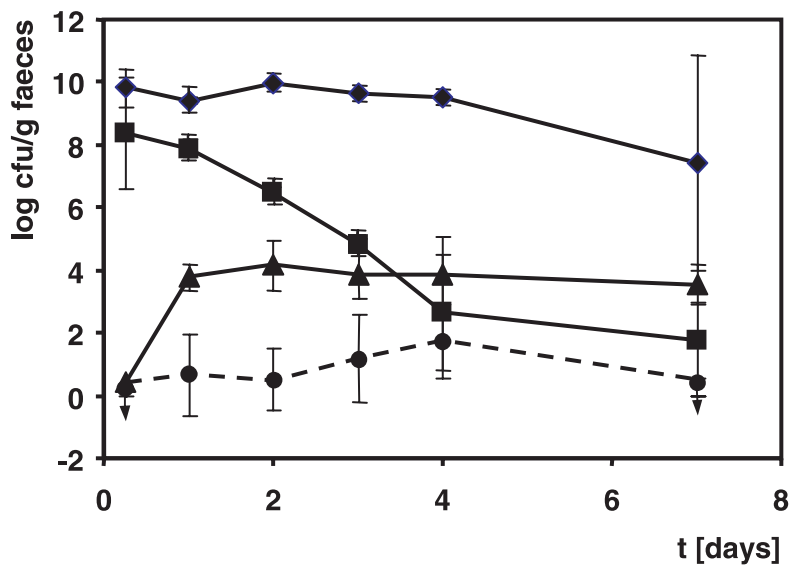

Figure 3. In vivo conjugation of Tn916-lux from L. lactis in mice associated with $E$. faecalis, single dose experiment. Diamonds indicate E. faecalis TTC00.0395, squares L. lactis $\mathrm{CA} 3$, triangles spores of thermoresistant $B$. stearothermophilus, circles E. faecalis TTC00.0395::Tn916-lux. Down arrows indicate values below the detection limit.

after an 8-hour transit (Fig. 3). This number decreased by approximately seven $\operatorname{logs}$ within a five-day period, similar to the titer of the B. stearothermophilus spores, which were used as indicators for passive transit. No transconjugant $E$. faecalis was detected during this time. Similarly, L. lactis was given orally continuously during 4 days (Fig. 4). Even under these potentially more promiscuous circumstances than the single inoculation, no enterococcal transconjugant was detected (Fig. 4). These observations were also true for an identical experiment where E. faecalis Z1666 was established as an alternative recipient strain (data not shown).

\section{DISCUSSION}

Our purpose was to determine an upper limit for HGT from GM LAB to a potential recipient in the DT. The two basic genetic elements used in this work (i.e. the helper/ mobilizable plasmid system and the conjugative transposon Tn916 derivative) have a broad host-range which makes them attractive tools for the construction of GM bacteria into which heterologous genetic material cannot be introduced by other current techniques (Bertram et al., 1991; Langella and Chopin, 1989; Poyart et al., 1995). Similar genetic elements could be used in the future for some applications leading to a release into open environments.

The helper/mobilizable plasmid system first investigated in this study was recently proposed for genetic engineering of non-transformable bacteria

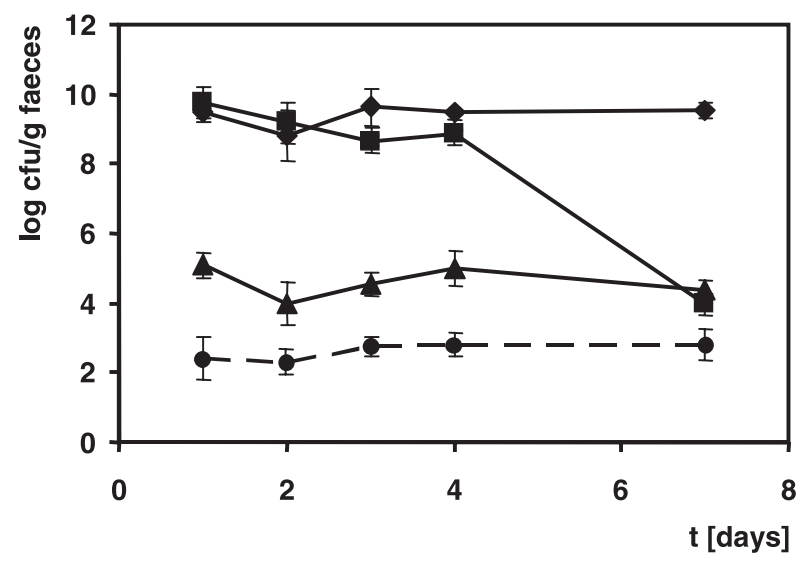

Figure 4. In vivo conjugation of Tn916-lux from L. lactis in mice associated with $E$. faecalis, continuous dose experiment (during 4 days). Diamonds indicate E. faecalis TTC00.0395, triangles L. lactis CA3 in the drinking bottle, squares L. lactis CA3 in the faeces, circles E. faecalis TTC00.0395::Tn916lux. Down arrows indicate values below the detection limit.

(Langella et al., 1993; Hickey et al., 2001; Thompson et al., 2001). The conjugative helper plasmid encodes all functions necessary for the transfer to a wide variety of recipient bacteria (Bougueleret et al., 1981; Buu-Hoi et al., 1984; Clewell, 1981; Engel et al., 1980; Gonzalez and Kunka, 1983; Pucci et al., 1988). The results from our in vitro experiments with this system indicate that it is indeed active, even when the co-mobilizable plasmid has been modified by the insertion of the lux genes. The mobilization rates observed in our transfer experiments to $E$. faecalis are lower than the rates observed in intraspecies conjugations with L. lactis $\left(5.2 \times 10^{-3}\right.$ transconjugants per donor; Langella et al., 1993). Although differences in the experimental conditions may be at stake, this could also be due to the transfer to a heterologous host or to the insertion of the foreign luciferase genes into the mobilizable construct. Our observations for the in vivo experiments showed that the native helper plasmid pIL205 can be introduced in all instances in to the enterococcal recipient. It is noteworthy that the fraction of the recipient population containing the conjugative plasmid, stays, once established, rather stable. It appears that there is either no secondary transfer from the enterococcal subpopulation containing the plasmid to the cells which have not acquired pIL205, or the transfer rate is in equilibrium with the loss of cells carrying the plasmid. The E. faecalis, which pick up the mobilizable plasmid, were found to be stable in monoassociated gnotobiotic mice, suggesting that the transconjugants have no ecological disadvantage. 
Conjugative DNA transfer in the mouse digestive tract

The differences in transfer for the 2 constructed mobilizable plasmids are quite remarkable, although a similar effect has previously been observed in intraspecies transfers in L. lactis, where a $1.5 \mathrm{~kb}$ fragment of the mob region inserted in two different orientations into the mobilizable plasmid was used $\left(2.8 \times 10^{-4} /\right.$ donor $v$ s. $5.8 \times 10^{-7} /$ donor (Langella et al., 1993). This orientation dependent effect may explain the difficulty to observe the transfer of pCAC2, which is evidently less frequently transferred than pCAC4. If the reduction is, as in this instance, also on the order of one to two logs, transfer of pCAC2 would be at the limit of detection as is here the case.

The second transfer system investigated in this work is the conjugative transposon Tn916-lux. Here, we establish a situation similar to a transposase-deficient minitransposon which is unable to escape its host cell. Indeed, we take advantage of in vitro observations that Tn916, once it has entered L. lactis, is unable to transfer actively to other cells due to the lack of an as yet unidentified host factor (Marra et al., 1999). Such a construct would permit an estimation of the transfer of chromosomal GM genes under optimized transfer-prone conditions. Since this situation is similar to the transfer of the transposase-less minitransposons, an upper limit for this type of constructs might be established.

No transconjugation from L. lactis::Tn916-lux to E. faecalis was observed in vitro, which is conform to the findings of Marra et al. (1999) and might lead to consider L. lactis::Tn916-lux as a suitable model for a "stable" genetic modification. The question was, if this would also apply to the situation in the DT of the E. faecalis associated mice. In this particular environment, the donor bacteria might eventually produce the lacking transfer factor and be able to support conjugation. However, the in vivo experiments did not give any transconjugants, even in continuous dosage experiments. But even if the construct is not self-transmissible out of L. lactis, genetic elements could be released in the environment since lysis of $L$. lactis has been described in the DT (Drouault et al., 1999). The release of the transposon DNA into the intestinal lumen may represent a risk if the naked DNA persists long enough to be taken up by other competent bacteria (Kharazmi et al., 2002), which at least was not observed for E. faecalis in our experiments. This might be different in a complex natural flora setting, where bacteria which can develop natural competence are also present.

\section{CONCLUSION}

We have studied the HGT from genetically modified L. lactis in the DT of mice under conditions considered to be some of the most favorable for the transfer in order to determine an upper limit of transfer rates for genetically modified organisms (GMOs) in this environment, i.e. we have created a worst-case scenario. However, in the case of the conjugative transposon, mimicking a mini transposon-derived GMO, no transfer of the element to E. faecalis was observed. For the plasmid model, a complete donor system (conjugative and mobilizable plasmids) was developed. Only few transconjugants were actually observed in vivo, but the population remains stable in the DT without any selection by antibiotic pressure. The risk of transfer thus appears very low but could not be excluded. It will now be necessary to study the transfer of these plasmids in mice associated with a complex human flora in order to find out if the gene transfer is reduced or enhanced by the autochthonous human flora.

\section{MATERIALS AND METHODS}

Bacterial strains and genetic constructions are listed in Table 1. The system for HGT by plasmid conjugation consists of two plasmids: the $\mathrm{tra}^{+} \mathrm{mob}^{+} \mathrm{Cm}^{\mathrm{r}}$ helper plasmid pIL205, a derivative of the Enterococcus agalacticae wide host range plasmid pIP501 (Langella et al., 1993) and the following construct. The P170 promoter from L. lactis was amplified from pAMJ295, a derivative of pAMJ752 (Madsen et al., 1999) with the primers D170 (TCCCCCGGGGGACAAGCTTTCGCGAGCTCGAG) and F170 (GCTCTAGAGCCGGATCCTACTAGACAACAAAATAG) (Madsen et al., 1999) and cloned as a SmaI-BamHI fragment in the pBSIIKS- vector (Stratagene). The resulting plasmid was inserted after linearization with SalI into pNLter7 (which carries lux genes), giving pNL2951a. The pBS vector of this plasmid was removed by digestion with $S a c I$ and replaced by the SacI linearized plasmid pIL1001, which carries the $2.2 \mathrm{~kb}$ $m o b$ region from pIP501 on a pBS KSII+ backbone. Plasmids with the two different relative orientations of the fragments were obtained and named pCAC2 and pCAC4, which were transferred by electroporation into L. lactis IL1403. The constructs carrying the $\operatorname{lux} A B$ genes are co-mobilizable but not self transmissible pAM $\beta 1$ derivatives (Renault et al., 1996). L. lactis containing the nonself transmissible but co-mobilizable pCAC2 or pCAC4 respectively were mated with L. lactis/pIL205 in order to construct strains, which contain the complete transfer system, i.e. both the helper and the mobilizable plasmids. This was achieved at rates of $1.3 \times 10^{-3}$ transconjugants per donor for L. lactis/pCAC2 as recipient and at $2.3 \times$ $10^{-3}$ transconjugants per donor for L. lactis/pCAC4 as 


\section{C.-A. Alpert et al.}

Table 1. Bacterial strains and genetic constructions.

\begin{tabular}{|c|c|c|}
\hline Strain/Plasmid & Description & Source or reference(s) \\
\hline JIM5245 & B. subtilis::Tn916-lux & Goupil-Feuillerat et al., 2000 \\
\hline IL1403 & L. lactis wild type & Chopin et al., 1984 \\
\hline IL3567 & E. coli $\mathrm{TG} 1 / \mathrm{pIL} 1001$ & Langella et al., 1993 \\
\hline IL1776 & L. lactis 1403 /pIL205 & Langella et al., 1993 \\
\hline TTC00.0395 & E. faecalis & $\begin{array}{l}\text { J. van der Vossen, TNO, } \\
\text { The Netherlands }\end{array}$ \\
\hline Z1666 & E. faecalis & P. Tailliez, INRA, France \\
\hline pIL1001 & $2.2 \mathrm{~kb} \mathrm{mob}$ from pIL205 in pBS & Langella et al., 1993 \\
\hline pNL2951a & $\begin{array}{l}\mathrm{P} 170_{\text {L. lactis }}:: l u x A B_{\text {Vibrio harveyi }} \\
\text { in pNL ter7S }\end{array}$ & $\begin{array}{l}\text { this work and Madsen et al., } 1999 \\
\text { Renault et al., } 1996\end{array}$ \\
\hline CA3 & L. lactis 1403::Tn916-lux & this work \\
\hline CA25 & L. lactis $1403 / \mathrm{pCAC} 2$ & this work \\
\hline CA27 & L. lactis $1403 /$ pCAC4 & this work \\
\hline CA31 & L. lactis 1403/pIL205/pCAC2 & this work \\
\hline CA33 & L. lactis 1403/pIL205/pCAC4 & this work \\
\hline CA61 & E. faecalis Z1666/pIL205/pCAC2 & this work \\
\hline
\end{tabular}

recipient, rates, which are comparable to the range reported earlier for the transfer of pIL205 in intraspecies conjugations with L. lactis strains (Langella et al., 1993). The Tn916-lux luciferase-targeted transposon contains the transcriptional fusion of the promoter for the acetolactate decarboxylase gene from $L$. lactis and the luciferase genes from Vibrio harveyi (aldBp::luxAB $\mathrm{Em}^{\mathrm{r}}$ ) inserted into the HindIII site of the tet $M$ gene from Tn916 (Corthier et al., 1998; Goupil-Feuillerat et al., 2000; Renault et al., 1996). Bacillus subtilis JIM 5245 containing Tn916-lux was used as initial donor of conjugative transposons.

\section{Luciferase tests}

Luciferase activity was measured on liquid samples as previously described (Corthier et al., 1998). Alternatively, the presence of the lux genes was confirmed by PCR using the primers CA203 (5' CTCACTTATCAGCCACCTGAG 3') and CA204 (5' CATTCACGTATGAGTCGTACC 3 '), which hybridized to $l u x A$ to give a product of $748 \mathrm{nt}$.

\section{Culture conditions}

Lactococcus lactis was grown at $30^{\circ} \mathrm{C}$ either in static liquid cultures or on plates with M17glc ( 5 g glucose per liter) as growth medium (Terzaghi and Sandine, 1975). Cultures of E. faecalis were similarly grown as static liquid cultures or on plates at $42{ }^{\circ} \mathrm{C}$ either on the same medium or MRS (DIFCO). When necessary, L. lactis or E. faecalis were incubated in anaerobic jars (GENbox anaer, bioMérieux, France); otherwise, all plates were incubated aerobically. Media for plates were solidified with $12 \mathrm{~g}$ of agar per liter. Selection for the presence of plasmids was done at $10 \mu \mathrm{g} . \mathrm{mL}^{-1}$ of chloramphenicol (Cm) (pIL205) or erythromycin (Em) (pCAC2 and pCAC4) respectively and with $5 \mu \mathrm{g} \cdot \mathrm{mL}^{-1}$ of Em for Tn916-lux. Liquid E. coli and B. subtilis cultures were grown with agitation in $\mathrm{LB}$ at $37{ }^{\circ} \mathrm{C}$. Thermoresistant B. stearothermophilus spores were used as transit markers and activated at $60{ }^{\circ} \mathrm{C}$ in G-spores medium according to the procedure described by Contrepois and Gouet (1969) for enumeration.

\section{Conjugation procedures}

\section{Plasmid conjugation}

For plasmid transfer from L. lactis to E. faecalis, $1 \mathrm{~mL}$ each of a fresh overnight culture was harvested by centrifugation and washed once with LCY (Liquid Casein Yeast extract; Raibaud et al., 1966). The pellets were suspended in $100 \mu \mathrm{L}$ of media and subsequently mixed. $100 \mu \mathrm{L}$ of the cell suspension was deposited in a square of $0.86 \mathrm{~cm}^{2}$ on a GN-6 Metricel gridded cellulose filter (Pall Corporation, Michigan, USA) placed on a MRS plate. Following incubation at $30{ }^{\circ} \mathrm{C}$ for $18 \mathrm{~h}$, cells 
Conjugative DNA transfer in the mouse digestive tract

were recovered from the filter by vortex mixing in $1 \mathrm{~mL}$ LCY, and appropriate dilutions were plated for selection and enumeration of parent and transconjugant cells. Titers for donor cells were determined on M17glc-Em$\mathrm{Cm}$ plates with aerobic incubation at $30{ }^{\circ} \mathrm{C}$. In contrast, recipient and transconjugant titers were determined on MRS selection plates aerobically incubated at $42{ }^{\circ} \mathrm{C}$, a non-permissive growth condition for $L$. lactis. Selection conditions for transconjugants were as follows: Cmcontaining medium was used to evaluate the transfer of pIL205 only, Em-containing medium for the transfer of the mobilizable plasmid, and Cm-Em-containing medium for the transfer of both plasmids.

\section{Conjugative transfer of the Tn916-Iux}

Transposon transfer and selection for transconjugants were essentially performed as for plasmid conjugation except that no filter system was used, i.e. the parent cell mix was directly deposited on the plate in a spot of about $20 \mathrm{~mm}$ diameter. Transfers from B. subtilis to L. lactis were performed on M17glc plates. Titers for donor cells were determined on LB-Em and aerobic incubation at $42{ }^{\circ} \mathrm{C}$, while recipient titers were determined on $\mathrm{M} 17 \mathrm{glc}$ plates with anaerobic incubation at $30{ }^{\circ} \mathrm{C}$. Transconjugants were selected on $\mathrm{M} 17 \mathrm{glc}-\mathrm{Em}$ plates anaerobically incubated at $30^{\circ} \mathrm{C}$. For transfers from L. lactis to E. faecalis, the selection for transconjugants was on MRS-Em at $42{ }^{\circ} \mathrm{C}$ in aerobic conditions, while for transfers from B. subtilis to E. faecalis the selection for transconjugants was on MRS-Em at $42{ }^{\circ} \mathrm{C}$ in anaerobic jars.

\section{Animal model}

Germfree $\mathrm{C} 3 \mathrm{He} / \mathrm{J}$ mice were reared in sterile Trexlertype isolators (La Calhène, Vélizy, France) fitted with a rapid transfer system, in an environmentally controlled room $\left(21^{\circ} \mathrm{C}\right)$ with a $12 \mathrm{~h}$ light-dark cycle. Mice had free access to irradiated food (UAR, Villemoisson, France) and sterilized water. Germfree adult male mice were used throughout the investigations. Bacteria were given to the mice for single dose experiments by oro-gastric intubations of $0.4 \mathrm{~mL}$ of washed concentrated overnight cultures resuspended in LCY, while for continuous dosage experiments the drinking water supply was replaced by bacterial solutions in LCY, which keeps the bacteria alive in the drinking bottle, but permits no multiplication. The bacterial suspensions were replaced daily by fresh solutions.
For each experiment four mice were inoculated per experiment and the faeces were collected and plated individually from at least three animals. Results are presented in the Figures with the standard error to the mean.

\section{ACKNOWLEDGEMENTS}

Philippe Langella, URLGA, INRA, kindly provided the plasmids and advice for the construction of the conjugative plasmid system. His critical reading of the manuscript is gratefully acknowledged. This work was supported by a grant from the European Union (GMOBILITY).

Received December 18, 2002; accepted June 11, 2003.

\section{REFERENCES}

Bertram J, Strätz M, Dürre P (1991) Natural transfer of conjugative transposon Tn916 between gram-positive and gram-negative bacteria. J. Bacteriol. 173: 443-448

Bougueleret L, Bieth G, Horodniceanu T (1981) Conjugative $\mathrm{R}$ plasmids in group $\mathrm{C}$ and $\mathrm{G}$ streptococci. J. Bacteriol. 145 : 1102-1105

Bumann D, Hueck C, Aebischer T, Meyer TF (2000) Recombinant live Salmonella spp. for human vaccination against heterologous pathogens. FEMS Immunol. Med. Microbiol. 27: 357-364

Buu-Hoi A, Bieth G, Horaud T (1984) Broad host range of streptococcal macrolide resistance plasmids. Antimicrob. Agents Chemother. 25: 289-291

Chopin A, Chopin MC, Moillo-Batt A, Langella P (1984) Two plasmid-determined restriction and modification systems in Streptococcus lactis. Plasmid 11: 260-263

Clewell DB (1981) Plasmids, drug resistance, and gene transfer in the genus Streptococcus. Microbiol. Rev. 45: 409-436

Contrepois M, Gouet P (1969) Utilisation d'une technique microbiologique pour la mesure de la vitesse des microparticules dans le tractus digestif des ruminants. C. R. Acad. Sci. (Paris) 268: 1757-1759

Corthier G, Renault P (1999) Future directions for research on biotherapeutic agents. In Elmer GW, McFarland L, Surawicz $\mathrm{C}$, Totowa NJ, eds, Contribution of genetic approaches on lactic acid bacteria. Biotherapeutic Agents and infectious diseases. Humana Press Inc, pp 269-304

Corthier G, Delorme C, Ehrlich SD, Renault P (1998) Use of luciferase genes as biosensors to study bacterial physiology in the digestive tract. Appl. Environ. Microbiol. 64: 27212722

Davison J (1999) Genetic exchange between bacteria in the environment. Plasmid 42: 73-91 
Davison J (2002) Towards safer vectors for the field release of recombinant bacteria. Environ. Biosafety Res. 1: 9-18

Drouault S, Corthier G, Ehrlich SD, Renault P (1999) Survival, physiology, and lysis of Lactococcus lactis in the digestive tract. Appl. Environ. Microbiol. 65: 4881-4886

Drouault S, Anba J, Corthier G (2002) Streptococcus thermophilus is able to produce a beta-galactosidase active during its transit in the digestive tract of germ-free mice. Appl. Environ. Microbiol. 68: 938-941

Engel HW, Soedirman N, Rost JA, van Leeuwen WJ, van Embden JD (1980) Transferability of macrolide, lincomycin, and streptogramin resistances between group A, B, and D streptococci, Streptococcus pneumoniae, and Staphylococcus aureus. J. Bacteriol. 142: 407-413

Gonzalez CF, Kunka BS (1983) Plasmid transfer in Pediococcus spp.: intergeneric and intrageneric transfer of pIP501. Appl. Environ. Microbiol. 46: 81-89

Goupil-Feuillerat N, Corthier G, Godon JJ, Ehrlich SD, Renault P (2000) Transcriptional and translational regulation of alpha-acetolactate decarboxylase of Lactococcus lactis subsp. lactis. J. Bacteriol. 182: 5399-5408

Gruzza M, Duval-Iflah Y, Ducluzeau R (1992) Colonization of the digestive tract of germ-free mice by genetically engineered strains of Lactococcus lactis: study of recombinant DNA stability. Microb. Releases 1: 165-171

Gruzza M, Fons M, Ouriet MF, Duval-Iflah Y, Ducluzeau R (1994) Study of gene transfer in vitro and in the digestive tract of gnotobiotic mice from Lactococcus lactis strains to various strains belonging to human intestinal flora. Microb. Releases 2: $183-189$

Hickey RM, Twomey DP, Ross RP, Hill C (2001) Exploitation of Plasmid pMRC01 to direct transfer of mobilizable plasmids into commercial lactococcal starter strains. Appl. Environ. Microbiol. 67: 2853-2858

Kharazmi M, Hammes WP, Hertel C (2002) Construction of a marker rescue system in Bacillus subtilis for detection of horizontal gene transfer in food. Syst. Appl. Microbiol. 25: 471-477

Langella P, Chopin A (1989) Conjugal transfer of plasmid pIP501 from Lactococcus lactis to Lactobacillus delbruckii subsp. bulgaricus and Lactobacillus helveticus. FEMS Microbiol. Lett. 51: 149-152

Langella P, Le Loir Y, Ehrlich SD, Gruss A (1993) Efficient plasmid mobilization by pIP501 in Lactococcus lactis subsp. lactis. J. Bacteriol. 175: 5806-5813

Madsen SM, Arnau J, Vrang A, Givskov M, Israelsen H (1999) Molecular characterization of the pH-inducible and growth phase-dependent promoter P170 of Lactococcus lactis. Mol. Microbiol. 32: 75-87

Marra D, Smith JG, Scott JR (1999) Excision of the conjugative transposon Tn916 in Lactococcus lactis. Appl. Environ. Microbiol. 65: 2230-2231

Mercenier A, Muller-Alouf H, Grangette C (2000) Lactic acid bacteria as live vaccines. Curr. Issues Mol. Biol. 2: 17-25

Mercenier A, Pavan S, Pot B (2003) Probiotics as biotherapeutic agents: present knowledge and future prospects. Curr. Pharm. Des. 9: 175-191

Poyart C, Celli J, Trieu-Cuot P (1995) Conjugative transposition of Tn916-related elements from Enterococcus faecalis to Escherichia coli and Pseudomonas fluorescens. Antimicrob. Agents Chemother. 39: 500-506

Pucci MJ, Monteschio ME, Kemker CL (1988) Intergeneric and intrageneric conjugal transfer of plasmid-encoded antibiotic resistance determinants in Leuconostoc spp. Appl. Environ. Microbiol. 54: 281-287

Raibaud P, Dickinson AB, Sacquet E, Charlier H, Mocquot G (1966) La microflore du tube digestif. I. Techniques d'étude et milieux de culture proposés. Ann. Inst. Pasteur 110: 568-590

Renault P (2002) Genetically modified lactic acid bacteria: applications to food or health and risk assessment. Biochimie 84: $1073-1087$

Renault P, Corthier G, Goupil N, Delorme C, Ehrlich SD (1996) Plasmid vectors for gram-positive bacteria switching from high to low copy number. Gene 183: 175-182

Roberts AP, Pratten J, Wilson M, Mullany P (1999) Transfer of a conjugative transposon, Tn5397 in a model oral biofilm. FEMS Microbiol. Lett. 177: 63-66

Robinson K, Chamberlain LM, Schofield KM, Wells JM, Le Page RW (1997) Oral vaccination of mice against tetanus with recombinant Lactococcus lactis. Nat. Biotechnol. 15: 653-657

Steidler L, Hans W, Schotte L, Neirynck S, Obermeier F, Falk W, Fiers W, Remaut E (2000) Treatment of murine colitis by Lactococcus lactis secreting interleukin-10. Science 289: 1352-1355

Terzaghi BE, Sandine WE (1975) Improved medium for lactic streptococci and their phages. Appl. Environ. Microbiol. 29: 807-813

Thompson JK, McConville KJ, Nicholson C, Collins MA (2001) DNA Cloning in Lactobacillus helveticus by the Exconjugation of Recombinant mob-Containing Plasmid Constructs from Strains of Transformable Lactic Acid Bacteria. Plasmid 46: 188-201 